\title{
Systematic characterization of novel IncRNAs responding to phosphate starvation in Arabidopsis thaliana
}

\author{
Jiapei Yuan ${ }^{1 \dagger}$, Ye Zhang ${ }^{1 \dagger}$, Jinsong Dong ${ }^{1}$, Yuzhe Sun², Boon L. Lim², Dong Liu ${ }^{{ }^{*}}$ and Zhi John Lu ${ }^{1 *}$ (D)
}

\begin{abstract}
Background: Previously, several long non-coding RNAs (IncRNAs) were characterized as regulators in phosphate (Pi) starvation responses. However, systematic studies of novel IncRNAs involved in the Pi starvation signaling pathways have not been reported.

Results: Here, we used a genome-wide sequencing and bioinformatics approach to identify both poly $(A)+$ and poly(A)- IncRNAs that responded to Pi starvation in Arabidopsis thaliana. We sequenced shoot and root transcriptomes of the Arabidopsis seedlings grown under Pi-sufficient and Pi-deficient conditions, and predicted 1212 novel IncRNAs, of which 78 were poly(A)- IncRNAs. By employing strand-specific RNA libraries, we discovered many novel antisense IncRNAs for the first time. We further defined 309 IncRNAs that were differentially expressed between $\mathrm{P}+$ and $\mathrm{P}$ - conditions in either shoots or roots. Through Gene Ontology enrichment of the associated protein-coding genes (co-expressed or close on the genome), we found that many IncRNAs were adjacent or coexpressed with the genes involved in several Pi starvation related processes, including cell wall organization and photosynthesis. In total, we identified 104 potential IncRNA targets of PHR1, a key regulator for transcriptional response to Pi starvation. Moreover, we identified 16 candidate IncRNAs as potential targets of miR399, another key regulator of plant Pi homeostasis.
\end{abstract}

Conclusions: Altogether, our data provide a rich resource of candidate IncRNAs involved in the Pi starvation regulatory network.

Keywords: Long ncRNAs, RNA-Seq, Phosphate starvation, Arabidopsis thaliana, Poly(A)+, Poly(A)-

\section{Backgrounds}

Plants possess an elaborate physiological system to respond to external stimuli and stress conditions [1], including phosphorus $(\mathrm{P})$ deficiency. As one of the major mineral macronutrients, $\mathrm{P}$ is essential for plant growth and development. It is an important structural element for many macromolecules and participates in many cellular activities, including energy transfer, photosynthesis (PS), carbon assimilation, and activity regulation of many critical enzymes [2]. Despite its outstanding effect on plant growth and crop productivity, inorganic

\footnotetext{
*Correspondence: liu-d@tsinghua.edu.cn; zhilu@tsinghua.edu.cn ${ }^{\dagger}$ Equal contributors

${ }^{1}$ MOE Key Laboratory of Bioinformatics, Center for Plant Biology, Center for Synthetic and Systems Biology and Tsinghua-Peking Joint Center for Life Sciences, School of Life Sciences, Tsinghua University, Beijing 100084, China Full list of author information is available at the end of the article
}

phosphate $(\mathrm{Pi})$, the predominant absorbable form of $\mathrm{P}$ for plant roots, is often insoluble and not utilizable for plant acquisition in most soils [3-6]. To cope with Pi deprivation, enhance $\mathrm{Pi}$ availability and maintain $\mathrm{Pi}$ homeostasis, plants have evolved a variety of adaptive strategies [7]. These strategies include remobilization and redistribution of internal $\mathrm{P}$ and enhanced assimilation of Pi from the environment [8-11]. Although these responses have been well characterized in many plant species, the underlying molecular mechanisms that regulate these responses remain largely unknown.

With the development of many genetic resources, several important transcription factors (TFs) have been identified during recent decades, including members of the MYB (PHR1 and MYB62), WRKY (WRKY75 and WRKY6), ZAT (ZAT6) and bHLH (bHLH32 and OsPTF1) families [12-18]. Among these TFs, PHR1 and its most closely 
related genes, PHL1 (PHR1-like 1) and PHL2, are central integrators in transcriptional regulation of $\mathrm{Pi}$ starvation responses $[19,20]$. Genome-wide characterization demonstrated that the promoter regions of many Pi starvation responsive genes contain the P1BS element, which can be recognized and bound by PHR1, PHL1, and PHL2 [19-21]. On the other hand, at the post-transcriptional level, miRNA399 has been identified as a key regulator of Pi homeostasis in post-transcriptional regulation [22]. The expression of miR399 is highly induced in both shoots and roots by a decrease in external Pi levels [23, 24]. MiR399 cleaves PHO2 mRNA, which encodes an ubiquitin E2 conjugase (UBC24). PHO2 has been demonstrated to regulate $\mathrm{Pi}$ uptake in roots and $\mathrm{Pi}$ translocation from roots to shoots by mediating protein degradation of high-affinity Pi transporters and PHOSPHATE1 (PHO1) $[25,26]$. Two $\mathrm{Pi}$ starvation-induced long non-coding RNAs, IPS1 and AT4, further modulate the activity of miRNA399, through a mechanism called 'target mimicry' [27]. IPS1-miR399 matching would therefore lead to the inhibition of miR399-mediated cleavage of $\mathrm{PHO} 2$ transcripts, thus influencing downstream Pi uptake and translocation [27]. Additionally, in rice, a cis-nature antisense transcript of OsPHO1;2 (cis- $\mathrm{NAT}_{\mathrm{PHO} ; 2}$ ) was shown to act as a translational enhancer of OsPHO1;2 [28]. Some other plant long non-coding RNA (lncRNA) candidates were also reported as potent regulators mediating gene expression and protein recruitment during stress responses [29-31]. For instance, two wellinvestigated lncRNAs, COOLAIR [32] and COLDAIR [33], were found to be involved in repression of $F L C$, a key suppressor of vernalization-controlled flowering in Arabidopsis. COOLAIR and COLDAIR are antisense and sense to the FLC transcript on the genome, respectively. The crucial functions of the above three lncRNAs demonstrate that antisense and intronic lncRNAs have a great effect on the regulation of cognate gene expression [34]. It is still unclear, however, whether the Arabidopsis genome contains other lncRNAs that participate in the adaptive response to Pi starvation.

In addition to individual studies of signaling components involved in $\mathrm{Pi}$ starvation responses, there have also been systematic studies using high-throughput array and sequencing data [21, 35-40]. For instance, it was suggested that roots and shoots are two independent regulons because of minor overlap between root and shoot transcriptomes [37]. Furthermore, a global characterization, based on a split-root system, classified the root transcripts response to local or systemic signals, respectively [36]. These transcriptomic analyses greatly improved our knowledge of protein-coding genes' regulatory networks. In addition to proteincoding mRNAs, microRNAs can also function as key regulators of $\mathrm{Pi}$ starvation stress signaling [41]. A comprehensive expression profiling of Pi-responsive small RNAs advanced our understanding of the regulation of Pi homeostasis mediated by small RNAs [42]. Although coding genes and miRNAs have been systematically investigated in $\mathrm{Pi}$ starvation responses, there has been no genome-wide study to identify and characterize novel lncRNAs participating in the response pathways to Pi starvation of Arabidopsis.

To systematically identify and characterize novel lncRNAs responding to $\mathrm{Pi}$ starvation, we developed a sequencing and bioinformatics framework for Arabidopsis thaliana. We first sequenced the poly(A) enriched [poly(A)+] and poly(A) depleted [poly(A)-] RNA libraries in the root and shoot tissues of Arabidopsis seedlings, either grown under Pi-sufficient $(\mathrm{P}+)$ or Pi-deficient $(\mathrm{P}-)$ conditions. We then identified and characterized approximately 1200 novel lncRNAs using a bioinformatics pipeline. These novel lncRNAs, as well as known lncRNAs previously annotated in TAIR10, were grouped into six clusters according to their differential expression levels between root and shoot tissues. Furthermore, 104 and 16 lncRNAs were predicted as potential regulatory targets of PHR1 and miR399, respectively. Overall, our work provides an abundant resource of candidate lncRNAs associated with $\mathrm{Pi}$ starvation signaling pathways and enriched the regulatory network of Pi starvation responses in Arabidopsis.

\section{Results}

Genome-wide identification of novel IncRNAs in Arabidopsis under $\mathrm{Pi}$ deficiency

To systematically identify lncRNAs that responded to Pi starvation, we performed strand-specific poly(A) + and poly(A) - RNA sequencing of 10-day-old Arabidopsis seedlings grown under $\mathrm{P}+$ and $\mathrm{P}-$ conditions. We chose 10-day-old seedlings with obvious Pi starvation phenotype in order to include the long-term Pi starvation responsive lncRNAs (Additional file 1: Figure S1). Roots and shoots were separately collected from various plant samples with two biological replicates (see Methods). We obtained approximately $400 \mathrm{M}$ pair-end reads, $94 \%$ of which could be mapped to the Arabidopsis genome (TAIR10) (Additional file 2: Table S1). From these short reads, we assembled 22,972 new transcripts (Additional file 1: Figure S2a). Subsequently, 1212 novel lncRNA transcripts were identified using a bioinformatics pipeline (Fig. 1a, Additional file 3, see Methods). In addition to the novel transcripts, $90 \%$ of the protein-coding genes and $83 \%$ of the TAIR10 lncRNAs could be fully assembled with our RNA-Seq data (Fig. 1b). Besides, we compared our defined 1212 novel lncRNAs with lncRNAs collected by PlncDB (see Methods) [43]. We found that many of the antisense lncRNAs have overlapped with natural antisense transcripts (NATs), 


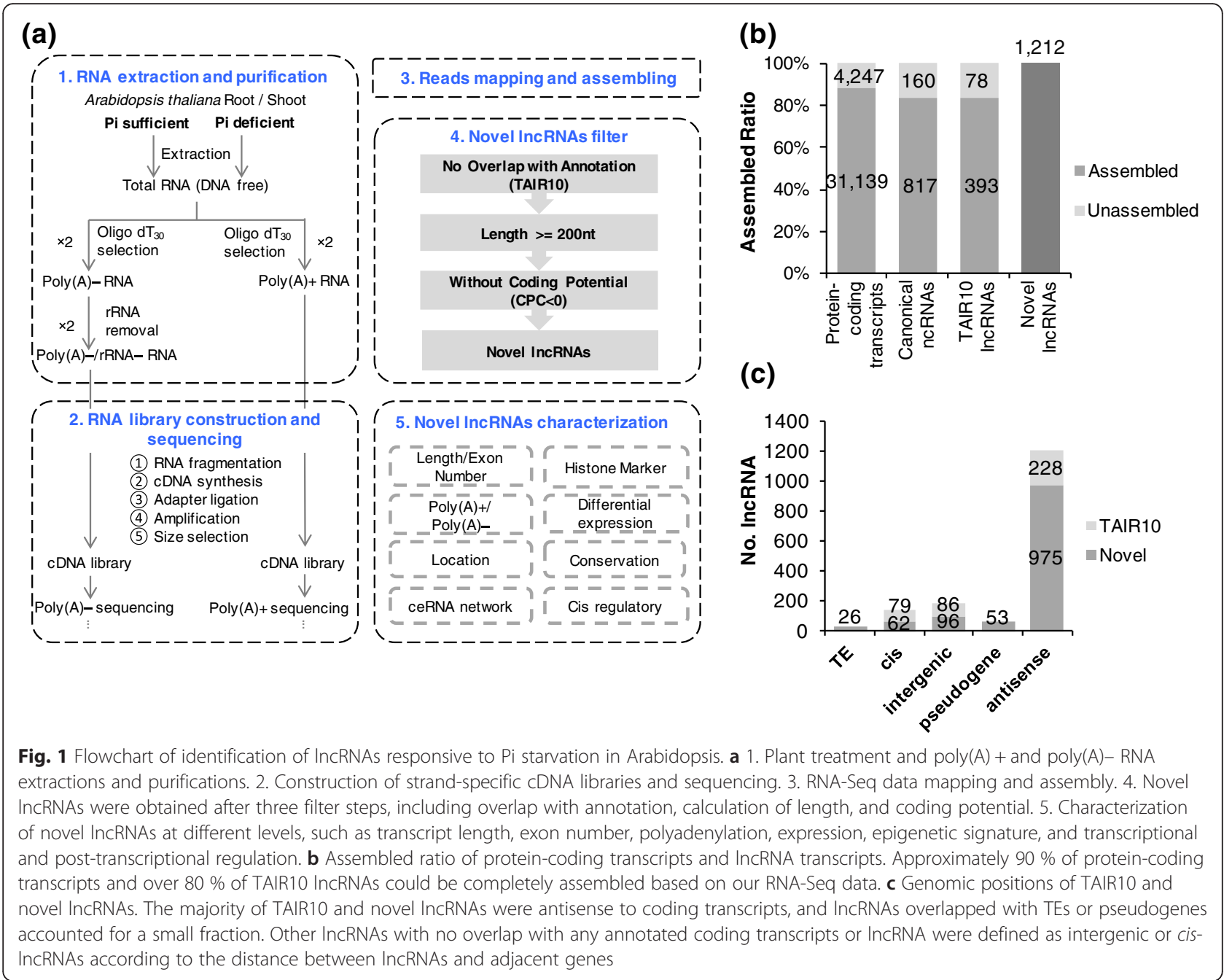

which were defined by previous studies based on EST and tilling array datasets [44-46] (Additional file 1: Figure S2b-d, Additional file 3).

We first compared the genomic positions of annotated (TAIR10) and novel lncRNAs (Fig. 1c). Because we used a strand-specific RNA library construction protocol, we were able to identify many (975) novel antisense lncRNAs. In addition, 79 and 62 of the TAIR10 and novel lncRNAs were defined as cis-lncRNAs, respectively, as they were close to ( $\leq 500 \mathrm{nt})$ protein-coding genes. We also found that 4 and $2 \%$ of the novel lncRNAs overlapped with pseudogenes and transposable element (TE)-related genes, respectively. The remaining lncRNAs came from intergenic regions, and were not close or antisense to any protein-coding genes.

\section{Characterization of the TAIR10 and novel IncRNAs}

We characterized various aspects of the TAIR10 and novel lncRNAs, including polyadenylation [Poly(A)] (Fig. 2a), exon number (Fig. 2b), expression level (Fig. 2c), and conservation (Fig. 2d), etc. (Additional file 1: Figures S3-S8).

We first classified all expressed transcripts into poly $(\mathrm{A})+$, poly $(\mathrm{A})-$ and bimorphic groups according to their relative abundance in poly $(\mathrm{A})+$ and poly $(\mathrm{A})-$ samples from roots or shoots under the same condition (see Methods). The biomorphic transcripts were those not showing distinguishable expression differences between poly(A) + and poly(A) - RNA-Seq data. Over $70 \%$ of the TAIR10 and novel lncRNAs were defined as poly(A) + transcripts (74\% in roots and $75 \%$ in shoots) under P+ condition (Fig. 2a, Additional file 1: Figure S3). Moreover, lncRNAs had lower exon numbers and transcript lengths than protein-coding transcripts (Fig. $2 \mathrm{~b}$ and Additional file 1: Figure S4, Additional file 2: Table S2). These observations were consistent with previous studies $[29,46]$, suggesting that alternative splicing events of protein-coding genes were more abundant than IncRNAs $[47,48]$. In addition, protein-coding transcripts showed higher expression levels than lncRNAs; 

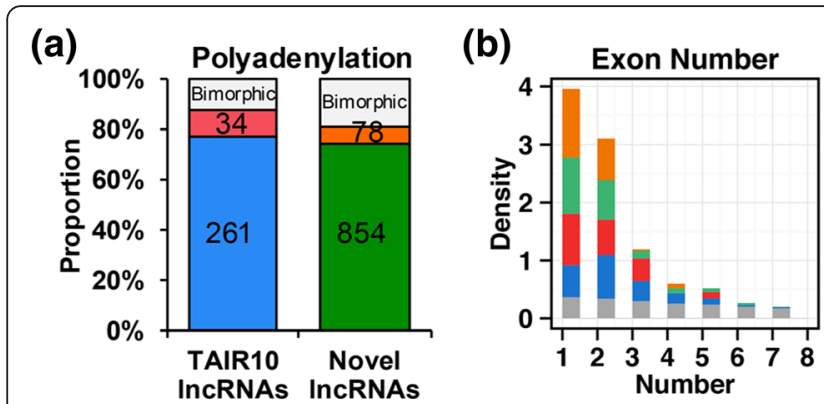

TAIR10 poly(A)+IncRNAs

- TAIR10 poly(A)-IncRNAs
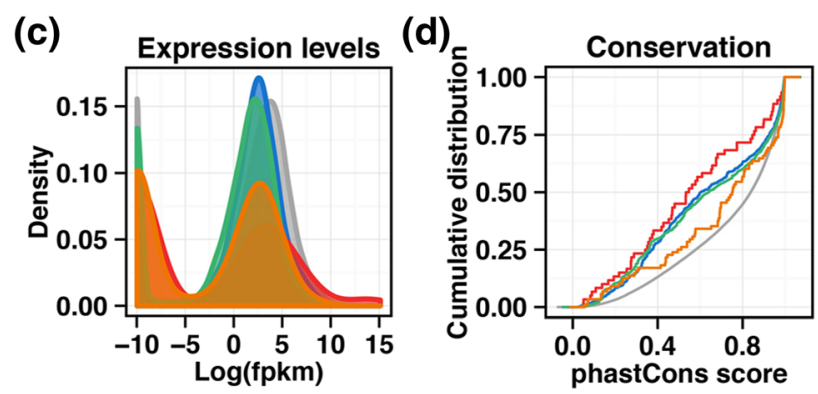

Novel poly(A)+IncRNAs

Novel poly(A)-IncRNAs
Protein-coding transcripts

Poly(A)+ $\square$ Poly(A)-
R: Root

S: Shoot

(e)

TAIR10 poly(A)+ IncRNA

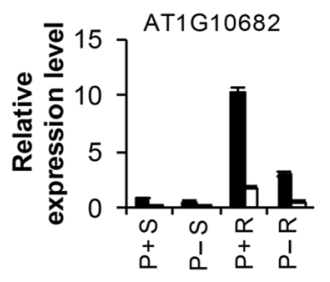

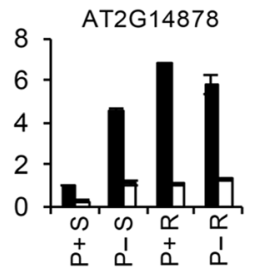

Novel poly $(A)+$ IncRNA

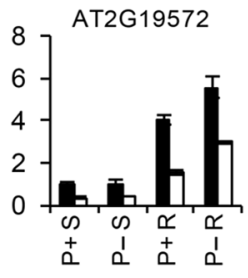

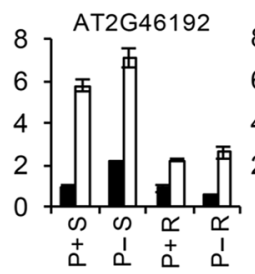

TAIR10 poly(A)- IncRNA
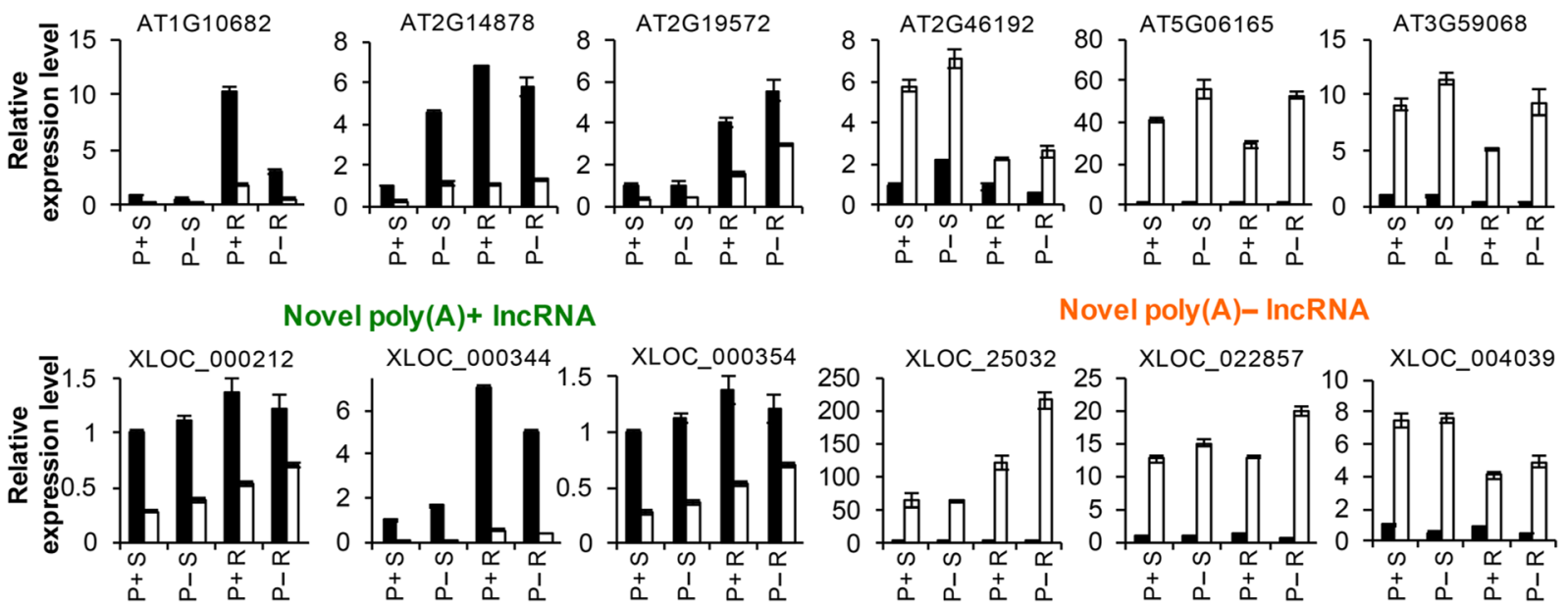

Fig. 2 Polyadenylation and characterizations of IncRNAs. a Poly(A) + and poly(A)- proportions of TAIR10 and novel IncRNAs. There were 1115 IncRNAs (accounting for over $70 \%$ ) classified as poly(A) + IncRNAs, and 112 classified as poly(A)- IncRNAs. b-d Comparison of poly(A) + and poly(A)- IncRNAs using exon number, expression level, and conservation. The IncRNAs exhibited lower exon number and conservation than protein-coding transcripts. Poly(A)- IncRNAs showed lower expression levels than poly(A) + IncRNAs. e Validation of poly(A) + and poly(A)IncRNAs using qRT-PCR. Poly(A) + IncRNAs were much more abundant in poly(A) + than poly(A)- samples; whereas, poly(A)- IncRNAs were mainly expressed in poly(A)- samples

and $\operatorname{poly}(\mathrm{A})+$ transcripts were usually more abundant than poly(A) - transcripts (Fig. 2c and Additional file 1: Figure S5). Although the lncRNAs were usually expressed at low levels, their activity was still well supported by different histone markers and DNase signals (Additional file 1: Figure S6). Finally, we showed that IncRNAs were less conserved than protein-coding transcripts (Fig. 2d, Additional file 1: Figures S7 and S8), which were also in agreement with previous lncRNA studies [29, 49].

To test the accuracy of our poly(A) classification, the expression levels of candidate lncRNAs in poly $(\mathrm{A})+$ and poly(A)- RNA samples were validated. We randomly selected eight candidates from each class of poly(A)+, poly(A) - and bimorphic lncRNAs for quantitative realtime PCR (qRT-PCR) validation. The qRT-PCR results confirmed all of the poly $(\mathrm{A})+$, seven poly $(\mathrm{A})-$ and six biomorphic lncRNAs defined by RNA-Seq data; and 18 of the validated lncRNAs were presented (Fig. $2 \mathrm{e}$ and Additional file 1: Figure S9).

\section{The IncRNAs differentially expressed in Pi-deprived roots} and shoots

We calculated the differentially expressed transcripts under $\mathrm{P}+$ and $\mathrm{P}-$ conditions, based on the RNA-Seq data (see Methods). In total, we identified 82 TAIR10 lncRNA and 227 novel lncRNA transcripts, which were significantly induced or repressed under Pi starvation condition (Additional file 4). We found some differentially expressed protein-coding transcripts that were consistent with previous studies (Additional file 1: Figure S10) [21, 35, 37, 50, 51]. Subsequently, we grouped these transcripts into six clusters according to the up-/ down- regulation levels in roots and shoots (Fig. 3a): transcripts were induced or repressed significantly in both roots and shoots (clusters 1 and 4), roots only (clusters 2 


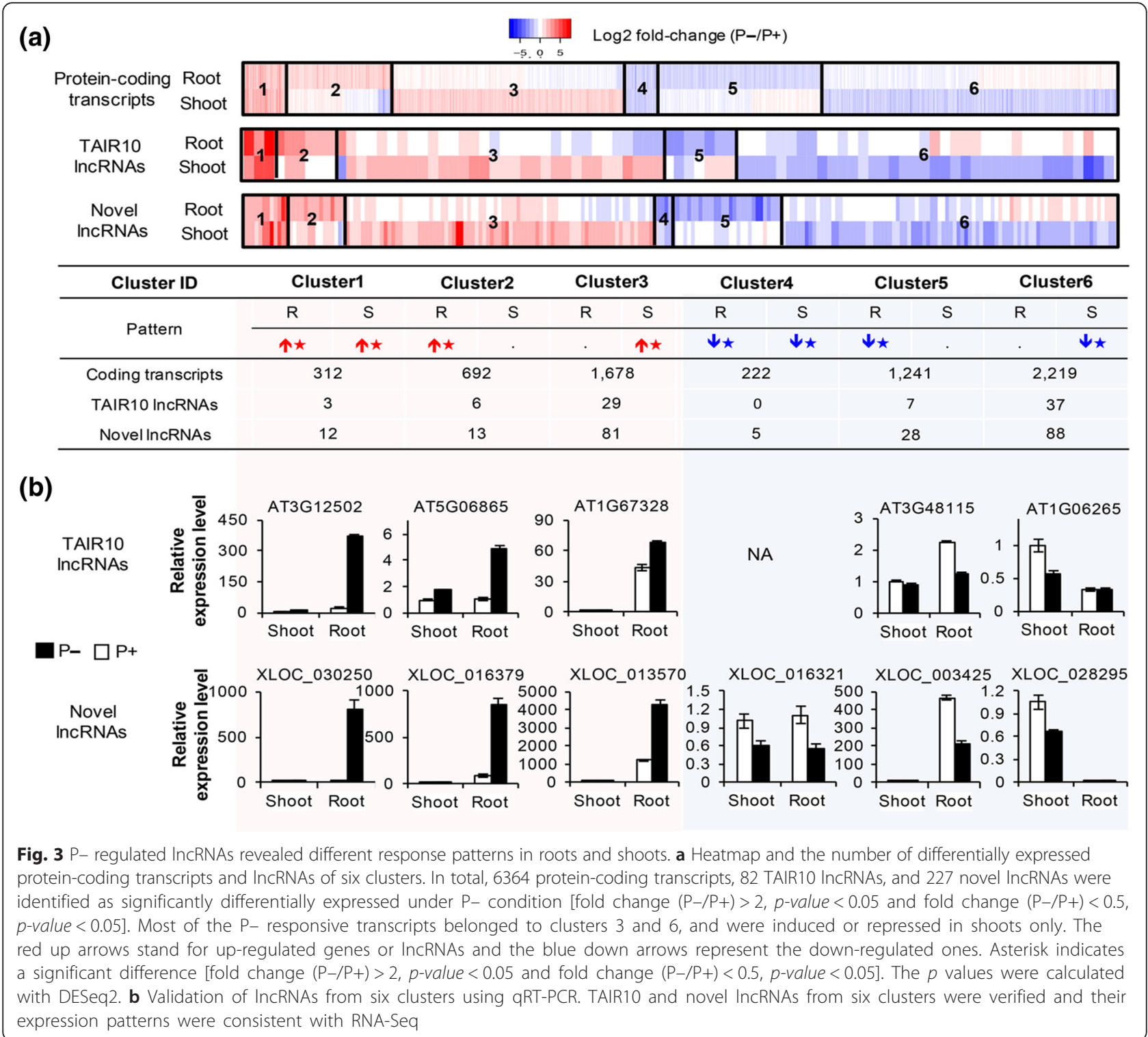

and 5), and shoots only (clusters 3 and 6). Interestingly, clusters 3 and 6 contained most of the differentially expressed transcripts for both lncRNAs and protein-coding transcripts. This suggested that more RNAs were regulated in shoots than in roots by $\mathrm{Pi}$ starvation. Then, we randomly selected 16 TAIR10 and 19 novel lncRNAs from the above clusters for the differential expression validation using qRT-PCR. Except for the absence of TAIR10 lncRNAs in cluster 4, 10 TAIR10, and 12 novel candidate lncRNAs from other clusters were verified in roots and shoots (Fig. 3b and Additional file 1: Figure S11). Moreover, the lncRNAs with and without poly(A) tails were also counted for each cluster (Additional file 1: Figure S12), based on the previous polyadenylation classification (Fig. 2a).
We also calculated alternative splicing (AS) events for these lncRNAs, based on the RNA-Seq data (Additional file 1: Figure S13). The main patterns of AS were retained intron (RI) and alternative 3 splice site (A3SS). Remarkably, the AS events were significantly enriched in lncRNAs from cluster 6 ( $\chi^{2}$ test, $\left.P<0.001\right)$. This result suggested that lncRNAs repressed in shoots (cluster 6) probably underwent regulation at both transcriptional and posttranscriptional levels, resulting in differential expression and AS under Pi starvation condition.

\section{Function and pathway prediction of IncRNAs that responded to $\mathrm{Pi}$ starvation}

We used two methods to associate and predict the potential functions of lncRNAs differentially expressed under $\mathrm{Pi}$ starvation: genomic position and expression 
pattern defined by the above six clusters. First, we tried to predict the functions of lncRNAs by linking them to their adjacent protein-coding genes on the chromosome (Fig. 4a). The antisense lncRNAs and cis-lncRNAs (close and on the sense strand) could serve as cis-regulatory elements to regulate the related protein-coding genes [32]. Consistent with the previous pattern (Fig. 1c), most of the differentially expressed lncRNAs in the above six clusters were antisense lncRNAs; and the antisense lncRNAs were mainly distributed in clusters 3 and 6 (Fig. 4a). Based on the Gene Ontology (GO) enrichment analyses, we found that protein-coding genes antisense to the up-regulated lncRNAs in cluster 3 (shoots only) were mainly related to cell wall thickening and cell surface signal transduction (Fig. 4b), which were important processes of Pi starvation responses [35].

In addition to utilizing the cis-regulatory relationships between lncRNAs and protein-coding genes, we then used the expression pattern to search the enriched functions. We found that the differentially expressed proteincoding genes in cluster 3 were also enriched with GO terms related to cell wall organization and modification (Fig. 4b). In other words, we found similar proteincoding genes using either genomic position relationship or co-expression pattern, suggesting that some differentially expressed lncRNAs and protein-coding genes in cluster 3 were antisense to each other. Some other Pi starvation-responsive GO terms were also revealed in other clusters (Fig. 4c). For instance, the up-regulated genes (clusters 1-3) had crucial roles in morphological processes, glycolipid metabolism, and ion transport. Additionally, some GO terms responding to nutrient starvation were enriched in clusters 1 and 2. Moreover, we found that 149 of 152 genes were co-expressed with their antisense lncRNAs significantly between $\mathrm{P}+$ and $\mathrm{P}$ - conditions (Additional file 5).

More interestingly, many down-regulated genes in clusters 5 (roots only) and 6 (shoots only) were enriched in the PS-related GO terms (Fig. 4c). Thus, representative genes for PS from cluster 5 and 6 , and their antisense lncRNAs (Additional file 6) from the same cluster were highlighted on the PS map (Additional file 1: Figure S14). That is, the labeled lncRNAs and coding genes in the map not only shared the same expression pattern (clusters 5 and 6), but were also antisense to each other. In general, representative genes for PS were greatly down-regulated by $\mathrm{Pi}$ deficiency in both roots and shoots. Additionally, the expression levels of many PS-related genes were more heavily suppressed in roots than in shoots (Additional file 1: Figure S15), and that is supported by previous studies [21, 35, 39, 50]. Comparing the suppressed PS genes in roots (cluster 5) and shoots (cluster 6) showed a universal decline in photosystem II. In contrast, the genes involved in photosystem I were more suppressed in roots than shoots.

Another lncRNA-gene regulation example was a $\mathrm{Pi}$ starvation-induced (PSI) lncRNA in cluster 2 (roots only), AT5G01595.1, which was antisense to a proteincoding gene, AtFer1. AtFer1 was reported to be a PSI gene that could be up-regulated by the well-known (a)

\begin{tabular}{|r|c|c|c|c|c|c|}
\hline & \multicolumn{7}{|c|}{ Cluster ID } \\
Location & $\mathbf{1}$ & $\mathbf{2}$ & $\mathbf{3}$ & $\mathbf{4}$ & $\mathbf{5}$ & $\mathbf{6}$ \\
\hline Cis & 2 & 5 & 6 & 0 & 7 & 6 \\
\hline Intergenic & 5 & 1 & 2 & 0 & 5 & 12 \\
\hline Pseudogene & 0 & 0 & 1 & 0 & 0 & 8 \\
\hline Antisense & 8 & 12 & 96 & 5 & 23 & 91 \\
\hline
\end{tabular}

(b)

Cluster 3

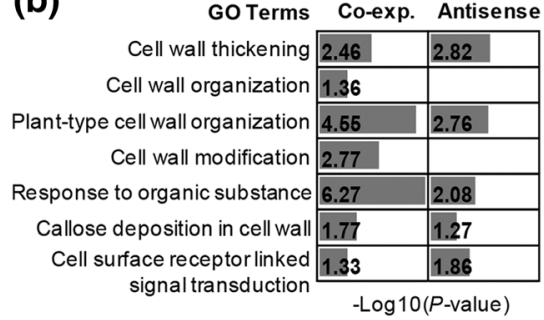

(c)

Cluster ID

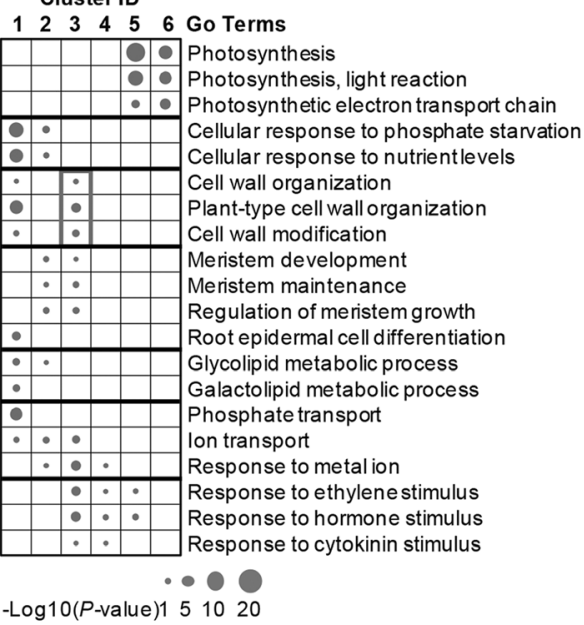

Fig. 4 Functional prediction of IncRNAs by co-position and co-expression. a Genomic positions of IncRNAs (including both TAIR10 and novel IncRNAs) from six clusters. Differentially expressed IncRNAs were mainly antisense IncRNAs. b Functional predictions of IncRNAs of cluster 3 via co-localization and co-expression. Protein-coding genes that were antisense to IncRNAs of cluster 3 were enriched in GO terms related to cell wall organization, which was consistent with the enriched functions of protein-coding genes from cluster 3. c GO of protein-coding genes from six clusters. Protein-coding genes were enriched in many Pi starvation responsive biological processes, such as photosynthesis, morphology change, root cell differentiation, phosphate transport, and hormone response 
transcription factor, PHR1 [52]. Due to the strand specificity of our RNA-Seq data, we clearly detected the differential expression of these two transcripts (Fig. 5a). The mapped RNA-Seq reads on each strand showed that both AT5G01595.1 and AtFer1 were induced by Pi deficiency. Furthermore, P1BS motifs (GNATATNC), which were recognized by PHR1 $[12,19]$, were identified at the promoter regions of both AtFer1 and AT5G01595.1. Moreover, qRT-PCR verified that AtFer1 and AT5G01595.1 were less induced in the phr1 mutant (Additional file 1: Figure S16). All of the above indicated that AT5G01595.1 was probably directly regulated by PHR1, and was involved in the Pi starvation signaling pathway.

Pi starvation-responsive IncRNAs were preferentially regulated by PHR1 in roots

In addition to the above example of AT5G01595.1, we examined whether all the differentially expressed lncRNAs contained P1BS motifs at their promoter regions (Table 1 and Additional file 7). We defined the upstream 2-kb of transcripts as their promoters, and used FIMO [53] to find the P1BS sequence motifs (see Methods). The P1BS motif was significantly enriched in the promoters of the up-regulated lncRNAs (Fig. 5b) and protein-coding transcripts (Additional file 1: Figure S17) from clusters 1 (both roots and shoots) and 2 (roots only) ( $\chi^{2}$ test, $\left.P<0.01\right)$. Particularly, 73 and $68 \%$ of the lncRNAs from clusters 1 and 2 contained P1BS motifs in their promoter regions, respectively. However, only $40 \%$ of lncRNAs from cluster 3 (shoots only) contained P1BS motifs at promoters, and the fractions of lncRNAs containing a P1BS motif of clusters 5 and 6 (expressed in roots and shoots, respectively) were below $40 \%$. We chose all protein-coding transcripts $(35,386$ in total) and lncRNAs (1692 in total) as the background (controls) to survey the P1BS motif enrichment fraction at their promoter regions. We could see that motif prediction would generate many potential false positives, because the fractions of controls for both protein coding genes (Additional file 1: Figure S17a) and lncRNAs (a)

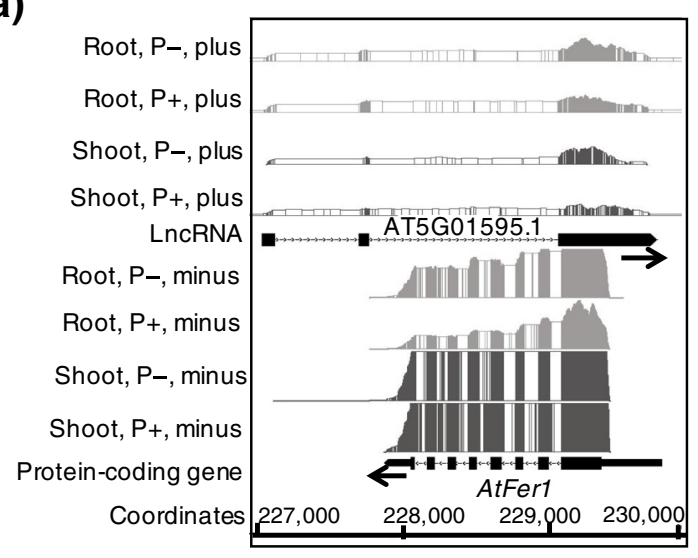

(c)

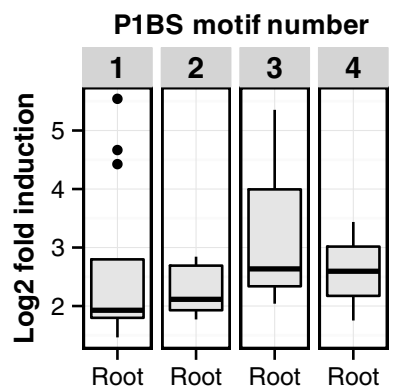

P1BS motif number

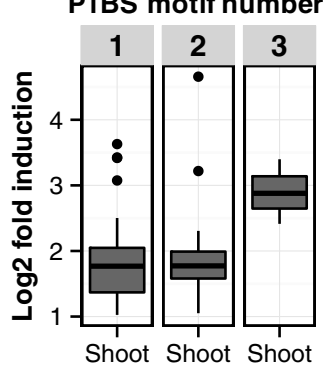

(b)

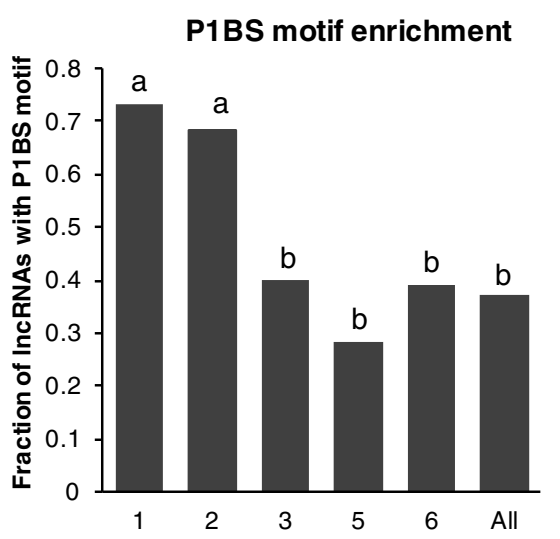

(d)

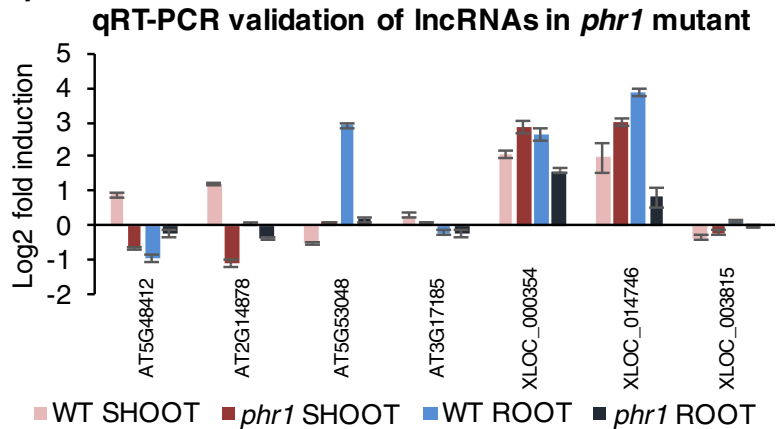

Fig. 5 P- regulated IncRNAs were potential targets of PHR1. a Integrated Genome Browser (IGB) visualization of expression level of IncRNA AT5G01595.1 and its antisense gene AtFer1. Both AT5G01595.1 and AtFer1 were induced in roots under P- condition and carried a P1BS motif at their promoter regions. $\mathbf{b}$ P1BS motifs were significantly enriched for IncRNAs in clusters 1 and 2 . The difference in ratios was tested using $X^{2}$ : a compared with $\mathbf{b}, P<0.01$; no significant difference within $\mathbf{a}$ and $\mathbf{b}$. All: All IncRNAs (1692) as control. c Correlation of P1BS motif number and fold induction of IncRNAs in roots and shoots. With increased P1BS content, fold induction of IncRNAs induced by Pi starvation also increased. The header numbers in the gray box indicate the P1BS motif number at the promoter regions of IncRNAs. $\mathbf{d}$ Validation of PHR1 potential targeted IncRNAs in the phr1 mutant by qRTPCR. The IncRNAs that PHR1 targeted were less induced/repressed in phr1 mutant 
Table 1 P1BS motif of PHR1 targeted protein-coding genes and IncRNAs

\begin{tabular}{|c|c|c|c|c|}
\hline GenelD/Name & No. Motif & Position of P1BS motif ${ }^{D}$ & Motif sequence & Cluster ID \\
\hline AtPAP10 & 1 & -122 & GAATATTC & 2 \\
\hline$P A P 1^{a}$ & 2 & $-656,-191$ & GCATATAC,GAATATCC & 1 \\
\hline$A t A C P 5^{\mathrm{a}}$ & 1 & -288 & GAATATCC & 1 \\
\hline $\operatorname{AtSPX1^{a}}$ & 3 & $-124,-881,-100$ & GGATATTC,GAATATTC,GAATATTC & 1 \\
\hline $\mathrm{SQD} 1^{\mathrm{a}}$ & 1 & -663 & GAATATGC & 1 \\
\hline $\operatorname{AtIPS} 1^{\mathrm{a}}$ & 2 & $-763,-729$ & GCATATTC,GCATATTC & 1 \\
\hline $\mathrm{SQD2} 2^{\mathrm{a}}$ & 3 & $-188,-136,-572$ & GCATATGC,GTATATCC,GAATATTC & 2 \\
\hline$A t 4^{a}$ & 2 & $-1028,-490$ & GTATATGC,GCATATTC & 1 \\
\hline RNS $1^{a}$ & 1 & -188 & GTATATAC & 1 \\
\hline$A t P T 1^{\mathrm{a}}$ & 3 & $-1301,-1283,-200$ & GGATATTC,GCATATTC,GTATATAC & 3 \\
\hline AtPT2 $^{\mathrm{a}}$ & 3 & $-394,-388,-1349$ & GAATATGC,GCATATAC,GAATATAC & 1 \\
\hline AT5G53048 & 1 & -142 & GTATATTC & 1 \\
\hline AT1G21529 & 1 & -81 & GAATATCC & 1 \\
\hline AT3G57157 & 2 & $-1760,-240$ & GCATATGC,GAATATCC & 2 \\
\hline AT5G06865 & 2 & $-1673,-1199$ & GAATATTC,GTATATTC & 2 \\
\hline AT5G01595 & 1 & -1988 & GCATATTC & 2 \\
\hline XLOC_026999 & 3 & $-372,-139,-128$ & GCATATTC,GCATATTC,GAATATTC & 1 \\
\hline XLOC_001691 & 3 & -1391 & GTATATAC & 1 \\
\hline XLOC_013732 & 3 & $-39,-299,-150$ & GCATATTC,GAATATAC,GAATATTC & 1 \\
\hline XLOC_030250 & 1 & -69 & GAATATTC & 1 \\
\hline XLOC_025622 & 2 & $-243,-273$ & GTATATCC,GAATATAC & 1 \\
\hline XLOC_004968 & 1 & -183 & GAATATGC & 1 \\
\hline XLOC_032181 & 4 & $-427,-108,-1483,-79$ & GGATATCC,GGATATGC,GAATATCC,GGATATTC & 2 \\
\hline XLOC_006489 & 2 & $-1453,-191$ & GCATATGC,GCATATTC & 2 \\
\hline XLOC_010338 & 2 & $-1706,-488$ & GCATATCC,GTATATCC & 2 \\
\hline XLOC_013570 & 1 & -1796 & GAATATTC & 2 \\
\hline XLOC_005614 & 2 & $-588,-113$ & GCATATCC,GAATATTC & 2 \\
\hline XLOC_013661 & 1 & -204 & GTATATTC & 2 \\
\hline XLOC_014746 & 1 & -62 & GAATATGC & 2 \\
\hline XLOC_015182 & 1 & -78 & GAATATCC & 2 \\
\hline
\end{tabular}

Note:

${ }^{\mathrm{a}}$ Gene names listed in italics are Pi starvation induced protein-coding marker genes

${ }^{b}$ For protein-coding genes, the position is given for the most 5 -upstream nucleotide relative to the first ATG in the transcribed region. For IncRNAs, the position refers to the most 5'-upstream nucleotide relative to first nucleotide of transcripts

${ }^{\mathrm{C}}$ This table only lists targeted IncRNAs in cluster 1 and 2. Full table of PHR1 targeted genes and IncRNAs are listed in Additional file 7

(Fig. 5b) tended to be high (30-40\%). Therefore, we added other supporting evidences (i.e., DNase data and transcriptional response to Pi starvation) as other filters to predict the PHR1's targets (Additional file 7) (see Methods), which could remove about $80 \%$ of the positives predicted by motif only.

Moreover, we tested whether the numbers of P1BS sequence motifs at the promoter regions were correlated with differential expression levels of PHR1-targeted transcripts. We correlated the average number of P1BS motifs per transcript with the targets' expression foldchange induced by $\mathrm{Pi}$ starvation, for both up- regulated lncRNAs (Fig. 5c) and protein-coding transcripts (Additional file 1: Figure S18). We found that when P1BS motif number increased so too did the induction of lncRNAs in roots and shoots. Furthermore, we also observed that the positions of P1BS motifs tended to be closer to their targeted genes/lncRNAs from cluster 1 than target transcripts from other clusters (Additional file 1: Figure S19).

Finally, we randomly selected three protein-coding genes and five candidate lncRNAs with P1BS motifs at their promoter regions, and validated their expression change in the phr1 mutant using qRT-PCR. Both 
lncRNAs (Fig. 5d) and protein-coding genes (Additional file 1: Figures S20 and S21) showed lower fold-changes in the phr1 mutant than the control (Col-0) plant. We used two lncRNAs (AT3G17185 and XLOC_003815) with P1BS motifs but no expression changes as negative controls, and found their expression levels were not affected by PHR1 (Fig. 5d). These results demonstrated that the candidate lncRNAs associated with P1BS motifs were very likely regulated by PHR1 under Pi starvation condition.

\section{Pi starvation-responsive IncRNAs targeted by miR399}

MiR399 has previously been shown to be a crucial posttranscriptional regulator [54], and has been demonstrated to bind the mRNAs of the PHO2 and AT4/IPS1 lncRNA family [27, 55]. However, its targets at genomic scale are unknown, and long noncoding RNAs have been proven to serve as potential target mimics for miRNAs in plants [56]. Thus, we first used two small public RNA-Seq data sets $[42,57]$ to profile differentially expressed miRNAs under $\mathrm{P}+$ and $\mathrm{P}-$ conditions (Additional file 1: Figure S22). In total, 13 and 11 miRNAs were significantly up-regulated in roots and shoots, respectively.

Next, we predicted the potential targets of these differentially expressed miRNAs using psRobot [58]. We combined expression correlations of miR399 and its potential targets to obtain a competing endogenous RNA (ceRNA) network for miR399. The lncRNAs whose expression levels were negatively correlated with miR399 were shown in Table 2. Three lncRNAs (XLOC_020833, XLOC_001691 and XLOC_013661) were revealed to be potential targets of both PHR1 and miR399, indicating their feasible functions involved in the Pi starvation regulatory network (Tables 1 and 2, Fig. 6, and Additional file 7). There were a total of 42 potential targets of miR399 (Table 2), of which 16 were lncRNAs.

\section{Discussion}

With the advance of next-generation sequencing technology, many novel non-coding RNA transcripts have been found in different species. However, they were previously treated as transcriptional noise, because of their low expression levels and low evolutionary conservation $[59,60]$. Recently, many lncRNAs have been recognized as important regulators of a variety of biological processes [61, 62]. Based on strand-specific RNA library construction protocols, a powerful tool in identifying NATs, nearly 10,000 lncRNAs have been annotated in the human genome [63-66]. However, although plants exhibit complicated biochemical, physiological, and developmental responses to cope with $\mathrm{Pi}$ starvation stress, a genome-wide characterization of known and novel lncRNAs involved in these responses is still lacking. In this study, we optimized experimental protocols with both poly (A) + and poly(A) - samples to capture genome-wide lncRNAs dynamically regulated under Pi starvation condition in both roots and shoots (Fig. 2). This is the first work to globally identify lncRNAs that respond to Pi starvation. Compared with previous genomic studies [21, 35, 37, 50,51], we found many more Pi starvation-responsive protein-coding candidates with higher occurrences that in other studies (Additional file 1: Figure S10 and Additional file 4). However, in addition to the overlapped ones, we found that many differential expression genes we annotated were not reported in other studies and the repeatability of differential expression genes among other studies is also quite low (Additional file 1: Figure S10) [21, 35, 37, 50, 51]. It may be due to different growth stages and treatment conditions: we chose 10-day-old long-term Pi-starved seedlings grown on agar plates as plant material, which was the same as many previous studies [19, 20,67]; while some of the other studies used more than 20-day-old plant with short-term Pi starvation treatment $[35,51]$ and others cultured the plants with hydroponic media [21, 50] or rockwool cubes [37]. Furthermore, different differential expression calculation tools used in different studies might also contribute to the differentially expressed candidates.

Based on the GO enrichment analyses of coding genes sharing the same expression pattern with the candidate lncRNAs, we found that many nuclear genome encoded PS-related genes were suppressed in both shoots and roots (Fig. 4c and Additional file 6) [35]. Although roots are heterotrophic organs and the expressions of PS genes were severely inhibited in roots compared with shoots (Additional file 1: Figure S15), there was still a basal level expression of PS genes in roots (Additional file 6). This might be because the seedlings were grown on agar plates and the roots were in the presence of light, which is a signal required for chlorophyll accumulation in roots [68]. We further showed that the expressions of genes involved in photosystem II and the redox chain were further down-regulated in both shoots and roots and the expressions of genes related to photosystem I were only further suppressed in roots under Pi starvation condition (Additional file 1: Figure S14). Based on these analyses, we speculated that Pi deprivation in shoots caused an adaptive strategy to reduce the expressions of PS-related genes in shoots. More severe suppression of the expression of photosynthetic genes in roots under $\mathrm{Pi}$ starvation condition may avoid excess production of reactive oxygen species (ROS) caused by aberrant PS activity, which can greatly damage cells [69]. Previous study demonstrated that suppression of PS gene expression is required for sustaining root growth under Pi deficiency [67]. Moreover, we also uncovered many 
Table 2 Correlation between miR399 and potential target genes

\begin{tabular}{|c|c|c|c|c|c|}
\hline miRNA & Target & Function description of target ${ }^{a}$ & $\mathrm{PCC}^{\mathrm{b}}$ & Target score ${ }^{c}$ & Cluster ID \\
\hline miR399a & AtPT1 & Inorganic phosphate transporter 1-1 & -0.72 & 5 & 3 \\
\hline miR399a & SMXL5 & Clp amino terminal domain-containing protein & -0.72 & 5 & 1 \\
\hline miR399a & ECT2 & Physically interacts with CIPK1. & -0.71 & 4.5 & 3 \\
\hline miR399a & AtCS-C & Dehydratase epimerase/racemase deaminase & -0.70 & 4.8 & 2 \\
\hline miR399a & TIP4; 1 & Aquaporin TIP4-1, transporter & -0.68 & 4.8 & 3 \\
\hline miR399a & AtPT2 & Inorganic phosphate transporter $1-2$ & -0.67 & 5 & 1 \\
\hline miR399a & SPPL5 & Signal peptide peptidase-like 5 , aspartic protease & -0.67 & 5 & 6 \\
\hline miR399a & AtSCAR4 & Protein SCAR4 & -0.62 & 5 & 6 \\
\hline miR399a & AtPP2-A5 & Protein PHLOEM PROTEIN 2-LIKE A5 & -0.59 & 4 & 6 \\
\hline miR399a & AT3G18620 & DHHC-type zinc finger family protein & -0.59 & 4.8 & 3 \\
\hline miR399a & AtCFM2 & Involved in group I and group II intron splicing. & -0.59 & 4.5 & 6 \\
\hline miR399a & AT1G61860 & Protein kinase family protein & -0.58 & 4.8 & 3 \\
\hline miR399a & AT2G31150 & ATP binding / ATPase & -0.58 & 5 & 6 \\
\hline miR399a & AT3G44820 & Phototropic-responsive NPH3 family protein & -0.58 & 4.8 & 3 \\
\hline miR399a & IPGAM1 & 2,3-bisphosphoglycerate-independent phosphoglycerate mutase 1 & -0.57 & 5 & 3 \\
\hline miR399a & AT2G25420 & mRNA splicing factor esterase kinase inhibitor & -0.57 & 4 & 6 \\
\hline miR399a & AtOPR1 & 12-oxophytodienoate reductase 1 & -0.57 & 4.8 & 3 \\
\hline miR399a & AT4G19520 & TIR-NBS-LRR class disease resistance protein & -0.56 & 5 & 6 \\
\hline miR399a & OZS2 & Pectinesterase/pectinesterase inhibitor 3 & -0.55 & 4.8 & 3 \\
\hline miR399a & AT2G38740 & Phosphatase & -0.55 & 4.5 & 2 \\
\hline miR399a & BLH1 & BEL1-like homeodomain protein 1 & -0.53 & 4.2 & 3 \\
\hline miR399a & TGA7 & Transcription factor TGA7 & -0.51 & 5 & 3 \\
\hline miR399a & AT1G61590 & Protein kinase superfamily protein & -0.51 & 4.8 & 3 \\
\hline miR399a & CYP705A30 & Cytochrome P450, family 705, subfamily A, polypeptide 30 & -0.44 & 2 & 3 \\
\hline miR399a & $\mathrm{PHO} 2$ & Mediates degradation of $\mathrm{PHO} 1$ and $\mathrm{PHT} 1 \mathrm{~s}$ & -0.37 & 0.8 & / \\
\hline miR399a & NF-YA10 & Nuclear transcription factor $Y$ subunit A-10 & -0.10 & 2.5 & 1 \\
\hline miR399d & XLOC_001691 & / & -0.74 & 5 & 1 \\
\hline miR399b & XLOC_026270 & / & -0.68 & 5 & 6 \\
\hline miR399e & XLOC_013661 & / & -0.64 & 5 & 2 \\
\hline miR399b & XLOC_013840 & / & -0.63 & 4.5 & 6 \\
\hline miR399e & XLOC_026270 & / & -0.62 & 4.5 & 6 \\
\hline miR399e & XLOC_003248 & / & -0.60 & 5 & 3 \\
\hline miR399e & XLOC_001806 & / & -0.59 & 4.8 & 5 \\
\hline miR399a & XLOC_018338 & / & -0.58 & 4.5 & 5 \\
\hline miR399d & XLOC_027498 & / & -0.58 & 4.8 & 6 \\
\hline miR399d & XLOC_010238 & / & -0.57 & 4.8 & 3 \\
\hline miR399c-5p & XLOC_019368 & / & -0.57 & 5 & 4 \\
\hline miR399c-3p & XLOC_016349 & / & -0.53 & 4 & 6 \\
\hline miR399b & XLOC_020833 & / & -0.53 & 5 & 3 \\
\hline
\end{tabular}


Table 2 Correlation between miR399 and potential target genes (Continued)

\begin{tabular}{llllll}
\hline miR399a & XLOC_008029 & $/$ & -0.51 & 5 & 6 \\
miR399c-3p & XLOC_005358 & $/$ & -0.50 & 4.8 & 6 \\
miR399f & XLOC_026270 & $/$ & -0.50 & 4.5 & 6 \\
\hline
\end{tabular}

Note:

${ }^{a}$ Column3 describes functions of targeted genes of miR399

${ }^{b}$ PCC refers the expression correlation of miR399 and its target genes

'Target score is the target match score calculated by psRobot, and lower target score represents better base pair match between miRNA and targets

${ }^{\mathrm{d}}$ The last column indicates the cluster that target genes or IncRNAs belonging to

candidate lncRNAs antisense to these PS genes that may play potential roles in regulating the suppression of PS genes. The function of these lncRNAs should be further investigated.

Moreover, the sensitive strand-specific RNA library construction protocol [70] enabled us to identify many novel lncRNAs transcribed from antisense strand. Interestingly, dozens of protein-coding genes, which were antisense to lncRNAs from cluster 3, were involved in cell wall organization processes (Fig. 4a, b). Meanwhile, the cluster 3 genes directly defined by expression pattern also showed high relevance with GO terms related to morphological changes, including cell wall organization and meristem development (Fig. 4b, c). These analyses indicated that the expression levels of genes involved in cell wall organization were tightly associated/correlated with their antisense lncRNAs during Pi starvation in shoots. Another antisense example was AT5G01595.1 and AtFer1. Their expression levels were both induced by $\mathrm{Pi}$ starvation, and their promoters both contained P1BS motifs, which indicated that they were both regulated by PHR1 during Pi starvation (Fig. 5a and Additional file 1: Figure S16). AtFer1 is a ferritin, which is stored in plastids to buffer free iron and maintain iron homeostasis [71, 72]. Previous study highlighted the biochemical, physiological, and molecular link between iron and $\mathrm{Pi}$ homeostasis $[73,74]$. There is direct evidence that PHR1 can directly bind the promoter of AtFer 1 and up-regulate its expression under Pi starvation condition [52]. Taken together, our strand-specific RNA-Seq results revealed that antisense lncRNAs might have important roles in Pi starvation signaling pathways.

PHR1 and miRNA399 are two central transcriptional and post-transcriptional signal transducers in the regulatory network of Pi starvation responses. Thus, we conducted a genome-wide investigation of the P1BS motif in the promoter regions of lncRNAs and protein-coding transcripts. We found that the upstream regions of many differentially expressed lncRNA transcripts, as well as protein-coding transcripts, contained the P1BS motif (Table 1). In addition, most of these P1BS-associated transcripts were from clusters 1 and 2 (Fig. 5c and Additional file 1: Figure S17). These results indicated that PHR1 (and its homolog PHL1) mainly regulated the PSI genes in roots. This suggestion was supported by a previous split-root study [36]. However, many PSI genes in shoots only were less affected by PHR1 and their transcriptional regulators require further identification.

We also globally analyzed the regulatory network of miR399. We predicted $16 \operatorname{lncRNAs}$ and 26 proteincoding genes as miR399 potential targets by integrating the sequence and expression relevance (Table 2). Here, we calculated correlation coefficient of miR399 and its target genes using 8 matched small RNA-seq and long
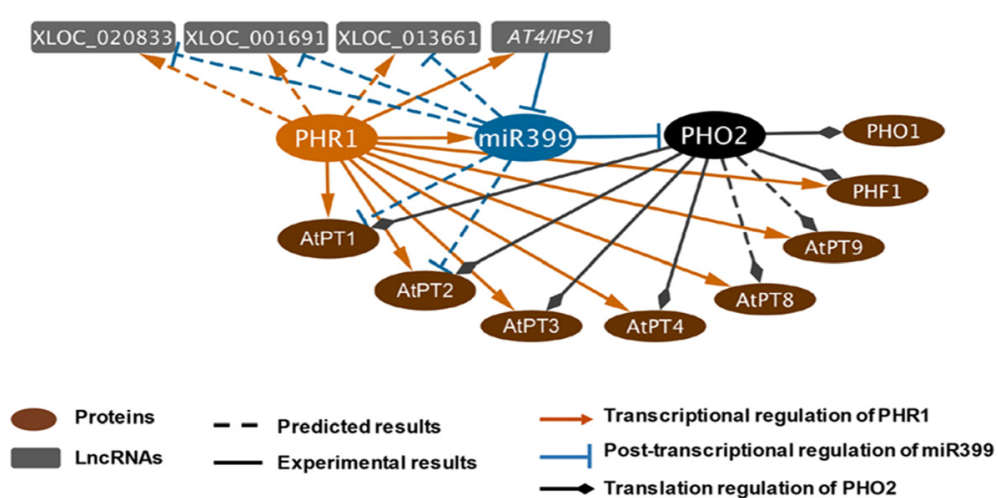

Fig. 6 Extended regulatory network of PHR1, miR399, PHO2, and their targets. We extended the regulatory network of PHR1 and miR399 by P1BS motif enrichment prediction and ceRNA network construction. Many other protein-coding genes and IncRNAs showed potential to be regulated by PHR1 and miR399 
RNA-seq datasets from different samples, including two replicates of $\mathrm{P}+$ in roots and shoots, and two replicates of $\mathrm{P}-$ in roots and shoots. However, when we defined a gene or lncRNA was induced or repressed under $\mathrm{Pi}$ starvation condition, we just compared the expression in $\mathrm{P}+$ and $\mathrm{P}-$ conditions. So the correlation of 8 samples could be inconsistent with the differential expression trend. A well-known example might explain this inconsistency is IPS1, it was found to be the target mimic of mi399 previously [27]. The expression level of IPS1 was reported to be up-regulated under $\mathrm{P}$ - condition, although miR399 was induced as well. Our prediction recovered $\mathrm{PHO} 2$, the well-known target of miR399 $[55,75]$. In addition, miR399 itself can be upregulated by PHR1 [55]. Two lncRNAs, IPS1 and At4, have been found to act as decoys of miR399 during Pi starvation [27, 76]. Integrating the above information, we proposed a $\mathrm{Pi}$ starvation signaling network illustrating the regulatory relationship among PHR1, miR399, PHO2, and their targets (Fig. 6). In addition to IPS1, we adapted a published method [56] to predict other potential target mimics of Pi deficiency regulated miRNAs (Additional file 2: Table S4). This method didn't need an expression correlation, but it had more requirements on pairing rules (e.g., a three nucleotide bulge at the middle of miRNA binding site within target mimic's sequence). In total, we have predicted 10 potential target mimics of $\mathrm{Pi}$ starvation responsive miRNAs (miR399, miR156 and miR169).

Furthermore, our study provided many candidate IncRNAs that could be simultaneously regulated by PHR1 and miR399 (Tables 1 and 2, and Additional file 7). Overall, we provided a set of research clues concerning the potential roles of the lncRNAs related to the signaling regulatory network under $\mathrm{Pi}$ starvation condition.

\section{Conclusions}

In summary, we systematically identified thousands of novel poly $(\mathrm{A})+$ and $\operatorname{poly}(\mathrm{A})-\operatorname{lnc} \mathrm{RNAs}$ related to $\mathrm{Pi}$ starvation responses in Arabidopsis. We further characterized the known and novel lncRNAs and provided a rich candidate resource for future study. This work also revealed that many lncRNAs had potential roles in regulating mRNA levels of many protein-coding genes involved in $\mathrm{Pi}$ starvation responses. In addition, we proposed the coding-non-coding network of Pi starvation responses, based on the PHR1-miR399-PHO2 pathway. The next challenge in the field will be further functional studies to elucidate the specific molecular roles of these candidate lncRNAs and their association/ interaction with other regulatory components involved in Pi starvation responses.

\section{Methods}

\section{Plant materials and growth conditions}

In this study, Arabidopsis wild type (Col-0) and phr1 mutant (Salk_067629) plants were all of the Columbia ecotype background. The Pi-sufficient medium (P+) contained half-strength MS salts [77] with $1 \%(\mathrm{w} / \mathrm{v})$ sucrose and $1.2 \%$ (w/v) agar (Sigma Cat. No. A1296). The formula of Pi-deficient medium ( $\mathrm{P}-$ ) was the same as for $\mathrm{P}+$ medium except for replacing $1.25 \mathrm{mM} \mathrm{K \textrm {H } _ { 2 }} \mathrm{PO}_{4}$ with $0.65 \mathrm{mM} \mathrm{K}_{2} \mathrm{SO}_{4}$. Seeds were surface sterilized with $20 \%$ (v/v) bleach for $15 \mathrm{~min}$ and washed three times in steriledistilled water. After that, seeds were sown on Petri plates containing $\mathrm{P}+$ or $\mathrm{P}-$ medium and stratified at $4{ }^{\circ} \mathrm{C}$ for $2 \mathrm{~d}$. The agar plates were placed vertically in a growth room at $22-24{ }^{\circ} \mathrm{C}$ and with a photoperiod of $16 / 8 \mathrm{~h}$ of light/dark. The light intensity was $100 \mu \mathrm{mol} \mathrm{m} \mathrm{m}^{-2} \mathrm{~s}^{-1}$. Two independent biological replicates of 10-day-old seedlings were collected and separated into roots and shoots for extraction of total RNA.

\section{Poly(A) + and poly(A)- RNA purification}

We adapted a published RNA purification method to extract poly $(\mathrm{A})+$ and poly $(\mathrm{A})$ - RNA components from total RNA [78]. Firstly, we used DNase I (Promega) to treat total RNA and then incubated the DNA-free RNA with oligo(dT) magnetic beads (Oligotex mRNA Mini Kit, Qiagen). After the incubation, poly $(\mathrm{A})+$ RNAs that were bound to the beads were isolated using centrifugation and resuspension. Poly(A)- RNAs, which were retained in the supernatant of incubation products, were processed with a Ribominus kit (RiboMinus ${ }^{\mathrm{TS}}$ Plant Kit for RNA-Seq, Invitrogen, A10838-08) to deplete ribosomal RNAs that account for the largest proportion of total RNA. Each reaction was performed twice to guarantee the purity of RNA components.

\section{Strand-specific RNA library construction and RNA sequencing}

We used a dUTP-based method to construct strandspecific RNA libraries for poly(A) + and poly(A) - RNAs. After fragmentation of RNAs, they were reverse transcribed to cDNAs and then ligated to adaptors. Finally, fragments in the range of 300-500 nt were recovered using a gel extraction kit from PCR products. Then we sequenced samples with an Illumina Hiseq 2000/2500 platform to obtain paired end reads.

\section{Novel IncRNA identification pipeline}

We used Tophat [79] to map reads to the TAIR10 [80] genome and used Cufflinks [81] to assemble transcripts based on 16 datasets of RNA-Seq samples. All the reads mapped to chloroplast and mitochondria genome were removed, and all protein-coding transcripts and lncRNAs that were used in this study were encoded by 
the nuclear genome. We assembled 60,027 transcripts that consisted of 31,139 protein-coding transcripts, 393 TAIR10 lncRNAs, 817 canonical ncRNAs, 862 pseudogenic transcripts, 3844 TE-related transcripts, and 22,972 new assembled transcripts. Other than proteincoding transcripts and TAIR10 lncRNAs, we followed the steps below to filter novel lncRNAs from the newly assembled transcripts: (i) 21,459 transcripts that overlapped with annotated coding-exons and non-coding RNA-exons in TAIR10 were filtered. Of these filtered transcripts, 21,434 had overlap with exons of proteincoding transcripts and TAIR10 lncRNA transcripts from the same strand. The other 24 transcripts had overlap with exons of TAIR10 lncRNA transcripts from the antisense strand; (ii) three transcripts of length $<200$ nt were filtered; and (iii) coding potential for each transcript was calculated using CPC [82], and 298 transcripts with coding potential $(\mathrm{CPC}>0)$ were filtered. Finally, 1212 transcripts that passed the above filter steps were retained as novel lncRNA transcripts. For the analyses below, the calculations were based on transcript level by default, except for the GO analysis of protein-coding genes.

\section{Classification of IncRNAs according to their genomic positions}

We categorized the genomic positions of lncRNAs according to the overlap with genomic elements. If an lncRNA overlapped with a pseudogene or TE by more than one nucleotide, it was defined as a pseudogenic or TE-related IncRNA. If an lncRNA was located at the antisense strand of a protein-coding transcript, it was defined as antisense lncRNA. Other transcripts without any overlap or antisense relationship with annotated genes were classified as intergenic lncRNAs, parts of which were defined as cis-lncRNAs when the distance between lncRNAs and adjacent genes was $\leq 500 \mathrm{nt}$.

\section{Comparison with IncRNAs collected by PIncDB}

We set two different criteria to overlap our defined lncRNAs with the lncRNAs in PlncDB: i. the overlapped length of a novel lncRNA with the collected IncRNA was more than $1 \mathrm{nt}$; ii. the ratio between the overlapped length and full length of a lncRNA was larger than 0.5. In the Additional file 3, we listed the overlapped ones based on criterion ii. PlncDB includes lncRNAs collected from five studies/resources, including EST datasets, two tilling array data sets (seedlings and seeds), RepTAS and RNA-seq studies [44-46].

\section{Classification of poly $(A)+$ and poly $(A)-$ IncRNAs}

We classified lncRNAs into two groups: poly(A) + and poly(A) - IncRNAs. The criterion to define the type of lncRNAs was to compare the expression level of lncRNA of corresponding poly $(\mathrm{A})+$ and $\operatorname{poly}(\mathrm{A})-$ samples.
Firstly, we filtered low-expressed transcripts that had RPKM (Reads Per Kilobase of transcript per Million mapped reads) $<0.1$ among 16 samples. For each transcript, we calculated a ratio of expression level (RPKM) of poly $(\mathrm{A})+$ over expression level of poly $(\mathrm{A})$ - sample. If the ratio for an IncRNA was $\geq 2$, we defined it as a poly $(\mathrm{A})+\operatorname{lncRNA}$; if the ratio was $\leq 0.5$, we defined it as a poly(A) - IncRNA; and if the ratio was within $0.5-2$, we classified them into a bimorphic group.

\section{Differential expressions under $\mathrm{P}+/ \mathrm{P}$ - conditions and transcript expression patterns in shoots and roots}

We used eXpress [83] to measure the expression level of transcripts. The lncRNAs were assigned corresponding expression values according to their polyadenylation type: $\operatorname{poly}(\mathrm{A})+$ and bimorphic lncRNAs used expression values from poly $(\mathrm{A})+$ samples; and expression levels of poly (A) - IncRNAs were based on poly(A) - samples. Then we used DESeq2 [84] to perform differential expression analysis. We calculated the fold-change of expression levels in Pi deficiency and Pi sufficiency and used $P$-values to filter the differentially expressed lncRNAs and protein-coding transcripts. We treated transcripts that had over two fold change with $P<0.05$ as significantly differentially expressed; if transcripts only had over two fold change but without $P<0.05$, we considered them not to be significantly expressed. Then we classified transcripts into six clusters according to their different levels of response in roots and shoots. Clusters 1 and 4 contained transcripts that were significantly induced or repressed in both roots and shoots. Clusters 2 and 5 included transcripts significantly induced or repressed only in roots. Clusters 3 and 4 consisted of transcripts significantly induced or repressed only in shoots.

\section{Validation of candidate IncRNAs with qRT-PCR}

Total RNA was extracted with the Trizol reagent (Invitrogen) from 10-day-old seedlings. Of DNasetreated RNA, $2 \mu \mathrm{g}$ was reverse transcribed in a $50-\mu \mathrm{L}$ reaction using Takara MLV-Reverse transcriptase with random primer (Thermo) according to the manufacturer's manual. cDNA was amplified using SYBR Premix Ex Taq (TaKaRa) on a Bio-Rad CFX96 realtime PCR detection system. Actin2 mRNA was used as an internal control. The genes and their primers are listed in Additional file 2: Table S3.

\section{GO enrichment and pathway enrichment analyses}

We used DAVID [85] for the GO enrichment analyses of protein-coding genes among the six clusters. We used balloonplot of ggplot2 in the R statistical package [86] to visualize the result. We used MapMan [87] for pathway analysis of protein-coding genes. The input values for MapMan were the fold-changes of genes between $\mathrm{P}-$ 
and P+ conditions (Additional file 1: Figure S14), or the fold-changes of genes between roots and shoots under $\mathrm{P}+$ condition (Additional file 1: Figure S15).

\section{P1BS motif search at the promoter regions and PHR1 target prediction}

As coding sequences have been annotated very well for protein-coding genes, we treated the 2-kb upstream from the first ATG of a gene as its promoter. When lncRNAs lacked annotation, we set the upstream $2 \mathrm{~kb}$ from the start site of transcripts as their promoters. We used MEME [85] to generate a position weight matrix (PWM) for a given motif, based on the published P1BS motif sequence [12], and then processed with FIMO [53] to predict the motif enrichment at promoter regions of genes and lncRNAs (cutoff: $P<1 \mathrm{e}-3$ ). As there were no available ChIP-Seq data for PHR1 in Arabidopsis, we also used other filter criteria to decrease the false positive rate of the target prediction based on motif search only. We required that these P1BS-motif enriched transcripts should respond to Pi starvation (significantly differentially expressed during $\mathrm{P}$ - treatment) and have chromatin accessibility (positive DNase value) at the promoter region (Additional file 7). We used the public DNase data [88] to measure the chromatin accessibility of the Arabidopsis whole genome.

\section{miRNA target prediction}

We used psRobot [58] to predict targets of miRNAs. We set miRNA target score $\leq 5$ as the cutoff for target prediction. We calculated Pearson's correlation coefficient (PCC) to represent expression value of miRNAs and long transcripts. The cutoff for expression correlation was $\mathrm{PCC}<0.5[89]$.

\section{Additional files}

Additional file 1: Supporting Figures S1-S22. This file contains all supporting figures. (DOCX $11257 \mathrm{~kb}$ )

Additional file 2: Supporting Tables S1-S4. This file contains all supporting tables. (DOCX $75 \mathrm{~kb}$ )

Additional file 3: Coordinates of novel IncRNAs in RefFlat format. This file contains the detailed coordinates of each novel IncRNAs, including the start and end positions of exons. (XLSX $136 \mathrm{~kb}$ )

Additional file 4: Differentially expressed protein-coding transcripts and IncRNAs under Pi starvation. This file contains all $\mathrm{P}$ - regulated proteincoding transcripts and IncRNAs. (XLSX $1710 \mathrm{~kb}$ )

Additional file 5: Protein-coding genes and their (anti-)co-expressed antisense IncRNAs. This file contains all (anti-)co-expressed genes and their antisense IncRNAs pairs. (XLSX $69 \mathrm{~kb}$ )

Additional file 6: Photosynthesis-related and $\mathrm{P}$ - repressed genes in roots and shoots. This file contains genes that are regulated by $\mathrm{Pi}$ starvation and involved in photosynthesis pathway. (XLSX $33 \mathrm{~kb}$ )

Additional file 7: LnCRNAs and protein-coding genes with P1BS motif at promoters. This files contains IncRNAs and protein-coding genes whose promoter regions contain P1BS motif. (XLSX 107 kb)

\section{Abbreviations}

ceRNA, competing endogenous RNA; GO, gene ontology; NAT, natural antisense transcript; NPA, poly(A)-; P-, Pi-deficient; P+, Pi-sufficient; PA, poly $(A)+$; $R$, root; $S$, shoot; $T F$, transcription factor

\section{Acknowledgements}

Not applicable.

\section{Funding}

This work was supported by National Key Basic Research Program of China (2012CB316503), National High-Tech Research and Development Program of China (2014AA021103), National Natural Science Foundation of China (31271402 and 31522030), and Tsinghua University Initiative Scientific Research Program (2014z21045). This work was also supported by the Computing Platform of National Protein Facilities (Tsinghua University). The funding for open access was provided by the National Natural Science Foundation of China (31271402)

\section{Availability of data and materials}

The datasets supporting the conclusions of this article are available in NCBI's Gene Expression Omnibus and are accessible through GEO accession number GSE76577 (http://www.ncbi.nlm.nih.gov/geo/query/ acc.cgi?token=obmdqiawzbshneh\&acc=GSE76577). The small RNA-seq data sets are accessible through SRA accession number SRP073352 [57] (http:// www.ncbi.nlm.nih.gov/sra/SRP073352) and through GEO accession number GSE17741 [42] (http://www.ncbi.n/m.nih.gov/geo/query/acc.cgi?acc=GSE17741).

\section{Authors' contributions}

ZL designed and supervised all aspects of the study; $Y Z$ and JD provided the plant samples for sequencing; $Y J$ purified the poly $(A)+$ and $\operatorname{poly}(A)$ RNA samples for the RNA library construction; YJ performed the RNA-seq data analysis; $Y Z$ did the validation experiments in the study; $Y J$ and $Y Z$ wrote the manuscript; $Z L, L D, B L$ and $Y S$ revised the manuscript for several times. All authors read and approved the final manuscript.

\section{Competing interests}

The authors declare that they have no competing interests.

\section{Consent for publication}

Not applicable.

\section{Ethics approval and consent to participate}

Not applicable.

\section{Author details}

${ }^{1}$ MOE Key Laboratory of Bioinformatics, Center for Plant Biology, Center for Synthetic and Systems Biology and Tsinghua-Peking Joint Center for Life Sciences, School of Life Sciences, Tsinghua University, Beijing 100084, China. ${ }^{2}$ School of Biological Sciences, the University of Hong Kong, Pokfulam Road, Hong Kong, China.

Received: 31 March 2016 Accepted: 12 July 2016

Published online: 18 August 2016

\section{References}

1. Hirayama T, Shinozaki K. Research on plant abiotic stress responses in the post-genome era: past, present and future. Plant J. 2010;61(6):1041-52

2. Theodorou ME, Plaxton WC. Metabolic adaptations of plant respiration to nutritional phosphate deprivation. Plant Physiol. 1993;101(2):339-44.

3. Marschner $\mathrm{H}$. Functions of mineral nutrients: macronutrients. Mineral Nutrition of Higher Plants. 1995;2:379-96.

4. Raghothama KG. Phosphate acquisition. Annu Rev Plant Physiol Plant Mol Biol. 1999:50:665-93.

5. Vance $C P$, Uhde-Stone C, Allan DL. Phosphorus acquisition and use: critical adaptations by plants for securing a nonrenewable resource. New Phytol. 2003;157(3):423-47.

6. Tang J, Leung A, Leung C, Lim BL. Hydrolysis of precipitated phytate by three distinct families of phytases. Soil Biol Biochem. 2006;38(6):1316-24.

7. Yuan H, Liu D. Signaling components involved in plant responses to phosphate starvation. J Integr Plant Biol. 2008;50(7):849-59. 
8. Poirier Y, Bucher M. Phosphate transport and homeostasis in Arabidopsis. Arabidopsis Book. 2002;1:e0024.

9. Lung S-C, Lim BL. Assimilation of Phytate-phosphorus by the Extracellular Phytase Activity of Tobacco (Nicotiana tabacum) is Affected by the Availability of Soluble Phytate. Plant and Soil. 2006;279(1):187-99.

10. Lung SC, Leung A, Kuang R, Wang Y, Leung P, Lim BL. Phytase activity in tobacco (Nicotiana tabacum) root exudates is exhibited by a purple acid phosphatase. Phytochemistry. 2008;69(2):365-73.

11. Lynch JP, Brown KM. Root strategies for phosphorus acquisition. In: The Ecophysiology of Plant-Phosphorus Interactions. Dordrecht: Springer; 2008 p. 83-116.

12. Rubio V, Linhares F, Solano R, Martin AC, Iglesias J, Leyva A, Paz-Ares J. A conserved MYB transcription factor involved in phosphate starvation signaling both in vascular plants and in unicellular algae. Genes Dev. 2001 15(16):2122-33.

13. Chen YF, Li LQ, Xu Q, Kong YH, Wang H, Wu WH. The WRKYG transcription factor modulates PHOSPHATE1 expression in response to low Pi stress in Arabidopsis. Plant Cell. 2009;21 (11):3554-66.

14. Chen ZH, Nimmo GA, Jenkins Gl, Nimmo HG. BHLH32 modulates several biochemical and morphological processes that respond to P-i starvation in Arabidopsis. Biochemical Journal. 2007:405:191-8.

15. Devaiah BN, Karthikeyan AS, Raghothama KG. WRKY75 transcription factor is a modulator of phosphate acquisition and root development in arabidopsis. Plant Physiol. 2007;143(4):1789-801.

16. Devaiah BN, Madhuvanthi R, Karthikeyan AS, Raghothama KG. Phosphate starvation responses and gibberellic acid biosynthesis are regulated by the MYB62 transcription factor in Arabidopsis. Mol Plant. 2009;2(1):43-58.

17. Devaiah BN, Nagarajan VK, Raghothama KG. Phosphate homeostasis and root development in Arabidopsis are synchronized by the zinc finger transcription factor ZAT6. Plant Physiol. 2007;145(1):147-59.

18. Yi K, Wu Z, Zhou J, Du L, Guo L, Wu Y, Wu P. OsPTF1, a novel transcription factor involved in tolerance to phosphate starvation in rice. Plant Physiol. 2005;138(4):2087-96

19. Bustos R, Castrillo G, Linhares F, Puga Ml, Rubio V, Perez-Perez J, Solano R, Leyva A, Paz-Ares J. A central regulatory system largely controls transcriptional activation and repression responses to phosphate starvation in Arabidopsis. PLoS Genet. 2010;6(9):e1001102.

20. Sun L, Song L, Zhang Y, Zheng Z, Liu D. Arabidopsis PHL2 and PHR1 act redundantly as the key components of the central regulatory system controlling transcriptional responses to phosphate starvation. Plant Physiol. 2016;170(1):499-514.

21. Misson J, Raghothama KG, Jain A, Jouhet J, Block MA, Bligny R, Ortet P, Creff A, Somerville $\mathrm{S}$, Rolland $\mathrm{N}$, et al. A genome-wide transcriptional analysis using Arabidopsis thaliana Affymetrix gene chips determined plant responses to phosphate deprivation. Proc Natl Acad Sci U S A. 2005;102(33):11934-9.

22. Chiou TJ, Lin SI. Signaling network in sensing phosphate availability in plants. Annu Rev Plant Biol. 2011;62:185-206.

23. Chiou TJ, Aung K, Lin SI, Wu CC, Chiang SF, Su CL. Regulation of phosphate homeostasis by MicroRNA in Arabidopsis. Plant Cell. 2006;18(2):412-21.

24. Fujii H, Chiou TJ, Lin SI, Aung K, Zhu JK. A miRNA involved in phosphatestarvation response in Arabidopsis. Curr Biol. 2005;15(22):2038-43.

25. Huang TK, Han CL, Lin SI, Chen YJ, Tsai YC, Chen YR, Chen JW, Lin WY, Chen PM, Liu TY, et al. Identification of downstream components of ubiquitinconjugating enzyme PHOSPHATE2 by quantitative membrane proteomics in Arabidopsis roots. Plant Cell. 2013;25(10):4044-60.

26. Liu TY, Huang TK, Tseng CY, Lai YS, Lin SI, Lin WY, Chen JW, Chiou TJ. PHO2-dependent degradation of $\mathrm{PHO} 1$ modulates phosphate homeostasis in Arabidopsis. Plant Cell. 2012;24(5):2168-83.

27. Franco-Zorrilla JM, Valli A, Todesco M, Mateos I, Puga MI, Rubio-Somoza I, Leyva A, Weigel D, Garcia JA, Paz-Ares J. Target mimicry provides a new mechanism for regulation of microRNA activity. Nat Genet. 2007;39(8):1033-7.

28. Jabnoune M, Secco D, Lecampion C, Robaglia C, Shu QY, Poirier Y. A rice cis-natural antisense RNA acts as a translational enhancer for its cognate mRNA and contributes to phosphate homeostasis and plant fitness. Plant Cell. 2013;25(10):4166-82.

29. Di C, Yuan J, Wu Y, Li J, Lin H, Hu L, Zhang T, Qi Y, Gerstein MB, Guo Y, et al. Characterization of stress-responsive IncRNAs in Arabidopsis thaliana by integrating expression, epigenetic and structural features. Plant J. 2014;80(5): 848-61.

30. Ben Amor B, Wirth S, Merchan F, Laporte P, d'Aubenton-Carafa Y, Hirsch J, Maizel A, Mallory A, Lucas A, Deragon JM, et al. Novel long non-protein coding RNAs involved in Arabidopsis differentiation and stress responses. Genome Res. 2009;19(1):57-69.

31. Shuai P, Liang D, Tang S, Zhang Z, Ye CY, Su Y, Xia X, Yin W. Genome-wide identification and functional prediction of novel and drought-responsive lincRNAs in Populus trichocarpa. J Exp Bot. 2014;65(17):4975-83.

32. Swiezewski S, Liu FQ, Magusin A, Dean C. Cold-induced silencing by long antisense transcripts of an Arabidopsis Polycomb target. Nature. 2009; 462(7274):799-U122.

33. Heo JB, Sung S. Vernalization-mediated epigenetic silencing by a long intronic noncoding RNA. Science. 2011;331(6013):76-9.

34. Zhang YC, Chen YQ. Long noncoding RNAs: new regulators in plant development. Biochem Biophys Res Commun. 2013;436(2):111-4.

35. Wu P, Ma L, Hou X, Wang M, Wu Y, Liu F, Deng XW. Phosphate starvation triggers distinct alterations of genome expression in Arabidopsis roots and leaves. Plant Physiol. 2003;132(3):1260-71.

36. Thibaud MC, Arrighi JF, Bayle V, Chiarenza S, Creff A, Bustos R, Paz-Ares J, Poirier Y, Nussaume L. Dissection of local and systemic transcriptional responses to phosphate starvation in Arabidopsis. Plant J. 2010;64(5):775-89.

37. Woo J, MacPherson CR, Liu J, Wang H, Kiba T, Hannah MA, Wang XJ, Bajic $\mathrm{VB}$, Chua NH. The response and recovery of the Arabidopsis thaliana transcriptome to phosphate starvation. BMC Plant Biol. 2012;12:1-22.

38. O'Rourke JA, Yang SS, Miller SS, Bucciarelli B, Liu J, Rydeen A, Bozsoki Z, Uhde-Stone C, Tu ZJ, Allan D, et al. An RNA-Seq transcriptome analysis of orthophosphate-deficient white lupin reveals novel insights into phosphorus acclimation in plants. Plant Physiol. 2013;161(2):705-24.

39. Secco D, Jabnoune M, Walker H, Shou H, Wu P, Poirier Y, Whelan J. Spatiotemporal transcript profiling of rice roots and shoots in response to phosphate starvation and recovery. Plant Cell. 2013;25(11):4285-304.

40. Cruz de Carvalho MH, Sun HX, Bowler C, Chua NH. Noncoding and coding transcriptome responses of a marine diatom to phosphate fluctuations. New Phytol. 2016;210(2):497-510.

41. Chiou TJ. The role of microRNAs in sensing nutrient stress. Plant Cell Environ. 2007;30(3):323-32.

42. Hsieh LC, Lin SI, Shih AC, Chen JW, Lin WY, Tseng CY, Li WH, Chiou TJ. Uncovering small RNA-mediated responses to phosphate deficiency in Arabidopsis by deep sequencing. Plant Physiol. 2009;151(4):2120-32

43. Jin J, Liu J, Wang H, Wong L, Chua NH. PLncDB: plant long non-coding RNA database. Bioinformatics. 2013;29(8):1068-71.

44. Matsui A, Ishida J, Morosawa T, Mochizuki Y, Kaminuma E, Endo TA, Okamoto M, Nambara E, Nakajima M, Kawashima M, et al. Arabidopsis transcriptome analysis under drought, cold, high-salinity and ABA treatment conditions using a tiling array. Plant Cell Physiol. 2008;49(8):1135-49.

45. Okamoto M, Tatematsu K, Matsui A, Morosawa T, Ishida J, Tanaka M, Endo TA, Mochizuki Y, Toyoda T, Kamiya Y, et al. Genome-wide analysis of endogenous abscisic acid-mediated transcription in dry and imbibed seeds of Arabidopsis using tiling arrays. Plant J. 2010;62(1):39-51.

46. Liu J, Jung C, Xu J, Wang H, Deng S, Bernad L, Arenas-Huertero C, Chua NH. Genome-wide analysis uncovers regulation of long intergenic noncoding RNAs in Arabidopsis. Plant Cell. 2012;24(11):4333-45.

47. Filichkin SA, Priest HD, Givan SA, Shen R, Bryant DW, Fox SE, Wong WK, Mockler TC. Genome-wide mapping of alternative splicing in Arabidopsis thaliana. Genome Res. 2010;20(1):45-58.

48. Marquez Y, Brown JW, Simpson C, Barta A, Kalyna M. Transcriptome survey reveals increased complexity of the alternative splicing landscape in Arabidopsis. Genome Res. 2012;22(6):1184-95.

49. Zhang YC, Liao JY, Li ZY, Yu Y, Zhang JP, Li QF, Qu LH, Shu WS, Chen YQ. Genome-wide screening and functional analysis identify a large number of long noncoding RNAs involved in the sexual reproduction of rice. Genome Biol. 2014;15(12):512.

50. Morcuende R, Bari R, Gibon Y, Zheng W, Pant BD, Blasing O, Usadel B, Czechowski T, Udvardi MK, Stitt M, et al. Genome-wide reprogramming of metabolism and regulatory networks of Arabidopsis in response to phosphorus. Plant Cell Environ. 2007;30(1):85-112.

51. Muller R, Morant M, Jarmer H, Nilsson L, Nielsen TH. Genome-wide analysis of the Arabidopsis leaf transcriptome reveals interaction of phosphate and sugar metabolism. Plant Physiol. 2007;143(1):156-71.

52. Bournier M, Tissot N, Mari S, Boucherez J, Lacombe E, Briat JF, Gaymard F. Arabidopsis ferritin 1 (AtFer1) gene regulation by the phosphate starvation response 1 (AtPHR1) transcription factor reveals a direct molecular link between iron and phosphate homeostasis. J Biol Chem. 2013;288(31): $22670-80$. 
53. Grant CE, Bailey TL, Noble WS. FIMO: scanning for occurrences of a given motif. Bioinformatics. 2011;27(7):1017-8.

54. Pant BD, Buhtz A, Kehr J, Scheible WR. MicroRNA399 is a long-distance signal for the regulation of plant phosphate homeostasis. Plant J. 2008;53(5):731-8.

55. Bari R, Pant BD, Stitt M, Scheible WR. PHO2, microRNA399, and PHR1 define a phosphate-signaling pathway in plants. Plant Physiol. 2006;141(3):988-99.

56. Wu HJ, Wang ZM, Wang M, Wang XJ. Widespread long noncoding RNAs as endogenous target mimics for microRNAs in plants. Plant Physiol. 2013; 161(4):1875-84.

57. Tao S, Zhang Y, Wang X, Xu L, Fang X, Lu ZJ, Liu D. The THO/TREX Complex Active in miRNA Biogenesis Negatively Regulates Root-Associated Acid Phosphatase Activity Induced by Phosphate Starvation. Plant Physiol. 2016; 171(4):2841-53.

58. Wu HJ, Ma YK, Chen T, Wang M, Wang XJ. PsRobot: a web-based plant small RNA meta-analysis toolbox. Nucleic Acids Res. 2012;40(Web Server issue):W22-8.

59. Ebisuya M, Yamamoto T, Nakajima M, Nishida E. Ripples from neighbouring transcription. Nat Cell Biol. 2008;10(9):1106-13.

60. Struhl K. Transcriptional noise and the fidelity of initiation by RNA polymerase II. Nat Struct Mol Biol. 2007;14(2):103-5.

61. Guttman M, Rinn JL. Modular regulatory principles of large non-coding RNAs. Nature. 2012;482(7385):339-46.

62. Lee JT. Epigenetic regulation by long noncoding RNAs. Science. 2012; 338(6113):1435-9.

63. Cabili MN, Trapnell C, Goff L, Koziol M, Tazon-Vega B, Regev A, Rinn J Integrative annotation of human large intergenic noncoding RNAs reveals global properties and specific subclasses. Genes Dev. 2011;25(18):1915-27.

64. Khalil AM, Guttman M, Huarte M, Garber M, Raj A, Morales DR, Thomas K, Presser A, Bernstein BE, van Oudenaarden A, et al. Many human large intergenic noncoding RNAs associate with chromatin-modifying complexes and affect gene expression. Proc Natl Acad Sci U S A. 2009;106(28):11667-72.

65. Schaefer M, Pollex T, Hanna K, Lyko F. RNA cytosine methylation analysis by bisulfite sequencing. Nucleic Acids Res. 2009;37(2):e12.

66. Zhu YY, Machleder EM, Chenchik A, Li R, Siebert PD. Reverse transcriptase template switching: A SMART (TM) approach for full-length CDNA library construction. Biotechniques. 2001:30(4):892-7.

67. Kang J, Yu H, Tian C, Zhou W, Li C, Jiao Y, Liu D. Suppression of photosynthetic gene expression in roots is required for sustained root growth under phosphate deficiency. Plant Physiol. 2014;165(3):1156-70.

68. Kobayashi K, Baba S, Obayashi T, Sato M, Toyooka K, Keranen M, Aro EM, Fukaki H, Ohta H, Sugimoto K, et al. Regulation of root greening by light and auxin/cytokinin signaling in Arabidopsis. Plant Cell. 2012;24(3):1081-95.

69. Li ZR, Wakao S, Fischer BB, Niyogi KK. Sensing and responding to excess light. Annu Rev Plant Biol. 2009;60:239-60.

70. Lu T, Zhu C, Lu G, Guo Y, Zhou Y, Zhang Z, Zhao Y, Li W, Lu Y, Tang W, et al. Strand-specific RNA-seq reveals widespread occurrence of novel cis-natural antisense transcripts in rice. BMC Genomics. 2012;13:721.

71. Briat JF, Duc C, Ravet K, Gaymard F. Ferritins and iron storage in plants. Bba-Gen Subjects. 2010;1800(8):806-14.

72. Ravet K, Touraine B, Boucherez J, Briat JF, Gaymard F, Cellier F. Ferritins control interaction between iron homeostasis and oxidative stress in Arabidopsis. Plant J. 2009;57(3):400-12.

73. Hirsch J, Marin E, Floriani M, Chiarenza S, Richaud P, Nussaume L, Thibaud MC. Phosphate deficiency promotes modification of iron distribution in Arabidopsis plants. Biochimie. 2006:88(11):1767-71.

74. Muller J, Toev T, Heisters M, Teller J, Moore KL, Hause G, Dinesh DC, Burstenbinder K, Abel S. Iron-dependent callose deposition adjusts root meristem maintenance to phosphate availability. Dev Cell. 2015;33(2):216-30.

75. Aung K, Lin SI, Wu CC, Huang YT, Su CL, Chiou TJ. pho2, a phosphate overaccumulator, is caused by a nonsense mutation in a microRNA399 target gene. Plant Physiol. 2006;141(3):1000-11.

76. Shin H, Shin HS, Chen R, Harrison MJ. Loss of At4 function impacts phosphate distribution between the roots and the shoots during phosphate starvation. Plant J. 2006:45(5):712-26.

77. Murashige T, Skoog F. A revised medium for rapid growth and bio assays with tobacco tissue cultures. Physiol Plant. 1962;15(3):473-97.

78. Yang L, Duff MO, Graveley BR, Carmichael GG, Chen LL. Genomewide characterization of non-polyadenylated RNAs. Genome Biol. 2011;12(2):R16.

79. Trapnell C, Pachter L, Salzberg SL. TopHat: discovering splice junctions with RNA-Seq. Bioinformatics. 2009;25(9):1105-11.
80. Lamesch P, Berardini TZ, Li D, Swarbreck D, Wilks C, Sasidharan R, Muller R, Dreher K, Alexander DL, Garcia-Hernandez M, et al. The Arabidopsis Information Resource (TAIR): improved gene annotation and new tools. Nucleic Acids Res. 2012:40(Database issue):D1202-10.

81. Trapnell C, Williams BA, Pertea G, Mortazavi A, Kwan G, van Baren MJ, Salzberg SL, Wold BJ, Pachter L. Transcript assembly and quantification by RNA-Seq reveals unannotated transcripts and isoform switching during cell differentiation. Nat Biotechnol. 2010;28(5):511-5.

82. Kong L, Zhang Y, Ye ZQ, Liu XQ, Zhao SQ, Wei L, Gao G. CPC: assess the protein-coding potential of transcripts using sequence features and support vector machine. Nucleic Acids Res. 2007:35(Web Server issue):W345-9.

83. Roberts A, Pachter L. Streaming fragment assignment for real-time analysis of sequencing experiments. Nat Methods. 2013;10(1):71-3.

84. Love Ml, Huber W, Anders S. Moderated estimation of fold change and dispersion for RNA-seq data with DESeq2. Genome Biol. 2014;15(12):550.

85. Huang DW, Sherman BT, Lempicki RA. Systematic and integrative analysis of large gene lists using DAVID bioinformatics resources. Nat Protoc. 2008:4(1):44-57.

86. Wickham H. SpringerLink (online service): ggplot2 elegant graphics for data analysis. In: Use R. New York: Springer-Verlag New York; 2009. 1 online resource.

87. Thimm O, Blasing O, Gibon Y, Nagel A, Meyer S, Kruger P, Selbig J, Muller LA, Rhee SY, Stitt M. MAPMAN: a user-driven tool to display genomics data sets onto diagrams of metabolic pathways and other biological processes. Plant J. 2004;37(6):914-39.

88. Zhang W, Zhang T, Wu Y, Jiang J. Genome-wide identification of regulatory DNA elements and protein-binding footprints using signatures of open chromatin in Arabidopsis. Plant Cell. 2012:24(7):2719-31.

89. Wang P, Ning S, Zhang Y, Li R, Ye J, Zhao Z, Zhi H, Wang T, Guo Z, Li X. Identification of IncRNA-associated competing triplets reveals global patterns and prognostic markers for cancer. Nucleic Acids Res. 2015;43(7): 3478-89.

\section{Submit your next manuscript to BioMed Central and we will help you at every step:}

- We accept pre-submission inquiries

- Our selector tool helps you to find the most relevant journal

- We provide round the clock customer support

- Convenient online submission

- Thorough peer review

- Inclusion in PubMed and all major indexing services

- Maximum visibility for your research

Submit your manuscript at www.biomedcentral.com/submit

O) BioMed Central 